\title{
Molecular diagnosis of Huntington disease in Portugal: implications for genetic counselling and clinical practice
}

\author{
Maria do Carmo Costa ${ }^{1}$, Paula Magalhães ${ }^{1}$, Fátima Ferreirinha ${ }^{1}$, Laura Guimarães ${ }^{1}$, \\ Cristina Januário $^{2,3}$, Isabel Gaspar ${ }^{4}$, Leal Loureiro ${ }^{1,5}$, José Vale ${ }^{4}$, Carolina Garrett ${ }^{6}$, \\ Fernando Regateiro $^{2,3}$, Marina Magalhães ${ }^{7}$, Alda Sousa ${ }^{1,8}$, Patrícia Maciel ${ }^{1,9}$ and \\ Jorge Sequeiros*,1,8
}

${ }^{1}$ UnIGENe, IBMC, Universidade de Porto, Portugal; ${ }^{2}$ Fac. Medicina, Universidade de Coimbra, Portugal; ${ }^{3}$ HUC, Coimbra, Portugal; ${ }^{4}$ Hosp Egas Moniz, Lisboa, Portugal; ${ }^{5}$ Hosp. S. Teotónio, Viseu, Portugal; ${ }^{6}$ Hosp. S. João, Porto, Portugal; ${ }^{7}$ Hosp. Sto. António, Porto, Portugal; ${ }^{8}$ Dep. Estudos das Populaçôes, ICBAS, Universidade do Porto, Portugal; ${ }^{9}$ ESCS, Universidade do Minho, Braga, Portugal

Huntington disease (HD) is a neurodegenerative, autosomal dominant disorder of late-onset, caused by the expansion of a CAG repeat in the coding region of the gene. Ours is the reference laboratory for genetic testing in HD, in Portugal, since 1998; 90.1\% of all 158 families known were identified for the first time, including patients with unusual presentation or without family history. A total of 338 genetic tests were performed: $\mathbf{2 3 4}$ for diagnosis, $\mathbf{9 6}$ for presymptomatic and four for prenatal testing (four were done for family studies). Most referring physicians were neurologists $(90.6 \%) ; 82.8 \%$ of all clinical diagnosis were confirmed, while $\mathbf{8 3 . 1 \%}$ of those sent for exclusion were in fact excluded. In presymptomatic testing, an excess of female subjects $(59.4 \%)$ was again verified; $37.5 \%$ of the consultands were found to be carriers. None of the foetuses, in four prenatal tests, were mutation carriers. One juvenile case was inherited from her mother. Our patient population is very similar to others described so far, namely in terms of mean age at onset and (CAG) ${ }_{n}$ distribution, except perhaps for a higher frequency of large normal (class 2) alleles (3.7\%). We also identify cases posing particular problems for genetic counselling, such as, 'homozygosity' that can pose a serious ethical dilemma, carriers of large normal alleles, and 'homoallelism' for a normal gene, which will demand further procedures and may delay results in presymptomatic and prenatal testing.

European Journal of Human Genetics (2003) 11, 872-878. doi:10.1038/sj.ejhg.5201055

Keywords: polyglutamine disorders; community genetics; genetic testing; homozygosity; homoallelism; intermediate alleles; ethical dilemma

Introduction

Huntington's disease (HD) is a progressive neurodegenerative disorder, with onset usually during adult life, asso-

*Correspondence: Dr Jorge Sequeiros, UnIGENe - IBMC, Universidade do Porto, R. Campo Alegre, 823, 4150-180 Porto, Portugal. Tel: +351 22 6074942; Fax: 35122 6099157; E-mail: jsequeir@ibmc.up.pt Received 17 December 2002; revised 28 April 2003; accepted 13 May 2003 ciated with involuntary choreic movements, motor problems, cognitive impairment and, often, a personality disorder tending to depression, anger and temper outbursts. $^{1}$ Prevalence of HD is estimated to be about 5-10:100000 in individuals of European descent, but is considered less common in southern Europe. ${ }^{2}$

HD is a dominant disorder caused by the expansion of a $(\mathrm{CAG})_{n}$ in the first exon of the $H D$ gene, located on chromosome $4 \mathrm{p} 16.3 .^{3}$ The repeat contains (class 1) 6-26 
CAGs in normal, stable alleles; (class 2) 27-35 CAGs in large normal, but expandable alleles, especially upon paternal transmission; (class 3) 36-39 CAGs in expanded alleles with reduced penetrance; and (class 4$) \geqslant 40$ CAGs in fully penetrant alleles. ${ }^{4}$

UnIGENe is the reference laboratory for HD testing in Portugal, having thus access to virtually all patients and families diagnosed since 1998, when diagnostic, presymptomatic and prenatal testing began to be offered. That same year, the lab entered the external quality assurance scheme offered by EMQN. ${ }^{5}$ Recommendations of the UK Clinical Molecular Genetics Society were adopted for internal quality assurance. The present results reflect the first 5 years of molecular diagnosis of HD in the country.

This was the first genetic study of HD in Portugal; its aims were: (1) to characterise clinical presentation, age at onset, family history, $(\mathrm{CAG})_{n}$ distribution, correlation between repeat size and age at onset, and geographic distribution of the HD Portuguese patients; (2) to assess the rate of positive molecular diagnosis; (3) to identify 'HDlike' patients and families, after exclusion of a molecular diagnosis of HD; (4) to assess the uptake of presymptomatic and prenatal testing in the country; and (5) to identify cases that pose special problems for genetic counselling and their frequency.

\section{Materials and methods} Ascertainment methods

Requests for testing were received from February 1998 to the end of December 2002.

Diagnostic tests are always performed upon referral from a physician, usually a neurologist, for confirmation or exclusion of a clinical diagnosis or suspicion of HD. A signed informed consent, and a form with clinical and family information are requested.

Presymptomatic and prenatal testing was offered only after adequate counselling and psychosocial evaluation at a genetics service; a specific consent form is mandatory. For presymptomatic testing, two blood samples obtained at different moments are requested. For prenatal testing, blood samples from both parents are also obtained.

Demographic and clinical data collected from each patient include signs and symptoms at time of referral, age of onset and a family history of any neurological and psychiatric symptoms.

Infantile and juvenile cases were defined as those with an onset below age 10 years, and between 11 and 19 years, respectively. ${ }^{6}$

\section{Subjects}

Non-Portuguese patients and families tested for HD (15 families from Brazil, two from Majorca, two from Cape Verde, one from Angola and one from the UK) were excluded for this study. A total of 338 samples were received in individuals of Portuguese origin: 234 for diagnostic (confirmation or exclusion), 96 for presymptomatic and four for prenatal testing; four were performed for family studies. We have thus registered 158 Portuguese families with HD; for some of the presymptomatic tests, a confirmation in a proband had been obtained abroad, before 1998 (the reason why the number of families is larger than our series of patients).

\section{Methods}

Genomic DNA was extracted from blood lymphocytes by standard methods. ${ }^{7}$ The CAG repeat size was assessed by polymerase chain reaction (PCR) analysis, using the RS1 and WP2 primers, flanking the CAG repeat. ${ }^{8}$ This was determined by denaturing $6 \%$ polyacrylamide gel electrophoresis, with an M13 sequence ladder, and visualized by autoradiography. The estimated error is \pm 1 CAG. We used, as positive controls, genomic DNA from (1) a patient with an allele containing 94 CAGs (the largest we have amplified so far), and from (2) a patient with 17 and 40 CAGs, previously confirmed by sequencing. Cases of homoallelism (defined as two alleles with exactly the same number of CAGs) were resolved (1) by PCR, using the RS1 and RS2 primers, which include both the CAG and the (also polymorphic) CCG repeat; ${ }^{8}$ and, (2) if the previous failed (ie, also same number of CCGs), Southern blotting was performed. ${ }^{9}$

\section{Statistical analysis}

$\chi^{2}$ analysis tested different proportions by gender. Student's $t$-test was used to compare mean age at onset or referral in two groups (male/female, confirmed/nonconfirmed). The strength of linear correlation between age at onset and repeat size was calculated by $R$-squared. A $P$-value $<0.05$ was considered statistically significant.

\section{Results}

\section{Results of all diagnostic tests}

Among all patients sent for diagnostic testing, 127 (54.3\%) were females, having a mean age at request \pm SD of $53.4 \pm 16.1$ years (range, $12-87$ ); and 107 (45.7\%) were males, with a mean age of $49.1 \pm 15.5$ years (range, $7-75$ ).

A genetic diagnosis of HD was obtained in a total of 151 (64.5\%) individuals, with a CAG expansion $\geq 36$ repeats (class 3 or 4 ). Their mean age was $51.5 \pm 14.2$ years (range, 10-77): 79 (52.3\%) were female individuals, with a mean age of $51.5 \pm 14.3$ years (range, $12-77$ ); and $72(47.7 \%$ ) were male individuals, with a mean age of $51.6 \pm 14.1$ years (range, 10-75).

In the remaining 83 (35.5\% of all requests), an exclusion of $\mathrm{HD}$ was made, as both alleles had CAG sizes of $<36$ repeats (classes 1 and 2). Their mean age at request was $51.3 \pm 18.8$ years (range, $7-87$ ), and their mean age at onset was $46.2 \pm 19.9$ years (range, 3-83). This group was 
composed by $48(57.8 \%)$ women, with a mean age of $56.6 \pm 18.3$ years (range, $12-87$ ), and 35 (42.2\%) men, with a mean age of $44.1 \pm 17.1$ years (range, $7-73$ ).

No differences were found, in relation to age at referral, age at onset, or sex composition, between patients genetically confirmed or excluded for HD.

Diagnostic tests were mainly requested by neurologists (90.6\%), although other clinicians, such as medical geneticists $(6.4 \%)$, neuropediatricians $(1.3 \%)$, psychiatrists $(0.9 \%)$, family physicians $(0.4 \%)$ and internists $(0.4 \%)$ have also sent some requests. The number of all diagnostic requests increased till 2000 and decreased during 2002.

\section{Requests for confirmation and exclusion of HD}

There were 169 requests for molecular confirmation (patients with a clinical diagnosis of HD), and 65 requests for exclusion (clinical diagnosis of HD uncertain or doubtful). Patients sent for confirmation of HD had a mean age at referral of $53.0 \pm 15.1$ years (range, 10-87), and a mean age at onset of $45.6 \pm 15.0$ years (range, $5-80$ ). Those sent for exclusion had a mean age of $47.4 \pm 17.3$ years (range, $7-84$ ) and a mean age at onset of $41.6 \pm 18.5$ years (range, 3-83). Mean age was significantly lower for patients sent for exclusion of HD $(P=0.046)$; however, no differences were found in terms of age at onset or sex proportion.

Among all requests sent for molecular confirmation of HD $(n=169), 140(82.8 \%)$ were actually confirmed, while 29 (17.2\%) patients were not ('false-positive' cases). Among these, 15 had family history of a similar disorder, eight had not, and it was unknown in six (Table 1). Eight patients with family history had somewhat unusual presentation: five had only chorea, two had tremor and dysarthria, and one had only dementia; the remaining seven had a typical clinical picture, except for a later age at onset (mean 66.4 years). Among eight cases without family history, four had typical symptoms and four did not (two had only chorea, one had chorea and generalised hypotonia, and one had only psychiatric symptoms and tics). In five cases, family history was not provided.

From all referrals for exclusion of HD $(n=65), 54(83.1 \%)$ were in fact excluded; 11 (16.9\%) patients had a CAG expansion $\geqslant 36$ repeats. Five of these had a family history (but no proband available), and presented only involun- tary and choreic movements, without cognitive impairment or motor problems; two had a typical presentation, but family history absent or unknown; the remaining four (6.1\%) had both family history and a typical presentation described, and the reasons why the clinical diagnosis had been questioned were not clear to us.

\section{Presymptomatic and prenatal testing}

All requests were received from clinical geneticists or neurologists in the counselling teams of the national programme for presymptomatic testing of late-onset disorders.

The mean age of subjects $(n=96)$ who performed presymptomatic testing was $38.0 \pm 13.2$ years (range, 19-71): $57(59.4 \%)$ were females, with a mean age of $39.2 \pm 13.9$ years (range, $19-71)$, and $39(40.6 \%)$ were males, with a mean age of $36.1 \pm 12.1$ years (range, 19-68). In 74 (77.1\%) cases there was a previous confirmation of HD in the family at our laboratory, whereas in 10 (10.4\%) HD had been confirmed in a relative, but before 1998 (at another lab).

Prior risk was of 75\% in two (2.1\%) subjects (both parents were carriers), $50 \%$ (parent affected or carrier) in 88 (91.7\%), 25\% (grandparent or other second degree relative affected) in five (5.2\%), and unknown (HD confirmed, but no information about the affected relative) in one $(1.0 \%)$ individual.

In $48(55.2 \%)$ presymptomatic tests, the molecular diagnosis had been made in the affected parent, and in the remaining in another relative. Mean age of transmitting parents was $61.3 \pm 8.5$ years (range, $41-77$ ); this was the father in 35 (36.5\%), the mother in 45 (46.9\%), and both in one $(1.0 \%)$ case; in $15(15.6 \%)$ cases, the sex of the affected parent was not made available to us.

Among all presymptomatic tests, 87 (90.6\%) were the first such request in their family.

Presymptomatic testing disclosed 36 (37.5\%) carriers of the HD mutation. In all four prenatal tests, the presence of an allele $\geqslant 36$ CAGs was excluded.

\section{HD families}

Among all patients confirmed by DNA analysis $(n=151)$, $121(80.1 \%)$ had a family history of HD, eight (5.3\%) had none and in $22(14.6 \%)$ it was not reported (Table 1).

Table 1 Family history of HD according to test results

\begin{tabular}{|c|c|c|c|c|c|c|c|c|c|c|c|c|c|c|}
\hline \multirow[b]{3}{*}{ Family history } & \multicolumn{6}{|c|}{ Referrals for HD confirmation } & \multicolumn{8}{|c|}{ Referrals for HD exclusion } \\
\hline & \multicolumn{2}{|c|}{ HD confirmed } & \multicolumn{2}{|c|}{$\begin{array}{c}(\geqslant 36 \text { CAGs }) \\
(C A G)_{n}\end{array}$} & \multicolumn{2}{|c|}{$\begin{array}{l}\text { HD excluded } \\
(<36 \text { CAGs) }\end{array}$} & \multicolumn{2}{|c|}{ HD confirmed } & \multicolumn{2}{|c|}{$\begin{array}{c}(\geqslant 36 \text { CAGs }) \\
(C A G)_{n}\end{array}$} & \multicolumn{2}{|c|}{$\begin{array}{l}\text { HD excluded } \\
(<36 \text { CAGs) }\end{array}$} & \multicolumn{2}{|c|}{ Total } \\
\hline & $n$ & (\%) & Mean & $S D$ & $n$ & $(\%)$ & $n$ & (\%) & Mean & " $S D$ & $n$ & $(\%)$ & $n$ & $(\%)$ \\
\hline Total & 140 & $(82.8)$ & 45.7 & 7.1 & 29 & $(17.2)$ & 11 & $(16.9)$ & 43.3 & 3.3 & 54 & $(83.1)$ & 234 & $(100.0)$ \\
\hline Present & 112 & (88.2) & 46.2 & 7.6 & 15 & $(11.8)$ & 9 & (23.7) & 43.4 & 3.4 & 29 & (76.3) & 165 & $(70.5)$ \\
\hline Absent & 7 & $(46.7)$ & 42.3 & 1.6 & 8 & $(53.3)$ & 1 & $(5.9)$ & 45 & - & 16 & (94.1) & 32 & (13.7) \\
\hline
\end{tabular}

Percentages are in relation to the type of request. 
The closest affected relative was the father in $56(46.3 \%)$, the mother in $31(25.6 \%)$, a sib in $15(12.4 \%)$, a seconddegree relative in five $(4.1 \%)$ patients and two cousins (1.7\%); no such information was available for $12(9.9 \%)$ cases. Among those with a family history, this was the first confirmation of HD in 109 families (90.1\%).

A total of 158 unrelated families were thus identified (in 15 , we just performed presymptomatic testing; previous confirmation had been done elsewhere).

The origin of each family was defined as the place of birth of their oldest known affected individual. There was no evidence for clustering of HD families in any particular region; families with HD seemed to be uniformly distributed, if population density was taken into account.

\section{CAG repeat length and age of onset}

Among all patients confirmed, we had information about age at onset in 120 , with a mean of $43.8 \pm 13.9$ years (range, 5-73). Three (5, 6 and 7 years) were infantile and one (19 years) was a juvenile case; 68 had onset ranging 20-49 years and 32 ranging 50-59 years; and 16 had onset after age 60, up to 73 years. There was no difference in sex distribution, either overall, or in each of the age-at-onset groups. We confirmed the inverse correlation between age of onset and $(\mathrm{CAG})_{n}$ size $\left(r^{2}=0.49\right)$ in our patients.

\section{Genetic instability of the CAG repeat}

Given the recent offer of testing, the number of parentoffspring pairs is still small $(n=21)$. In nine paternal transmissions, the CAG repeat expanded further in six (mean, +3.67 CAGs; range, +2 to +7 ) and maintained its size in three cases. In 12 maternal transmissions, the $(\mathrm{CAG})_{n}$ expanded further in two ( +1 unit in both), contracted in four (mean, -1.50 ; range, -1 to -2 ) and kept its size in six cases.

\section{Efficiency of each of the molecular diagnostic methods}

Amplification of the (CAG) ${ }_{n}$ by PCR, with primers RS1 and WP2, permitted an unequivocal diagnosis in 318 (94.1\%) of all tests (two alleles with different number of CAGs); it took, on average, 2-3 days. Cases of homoallelism for a normal gene were resolved using primers RS1 and RS2, in nine $(2.7 \%)$ cases; time needed was 5-6 days. The 11 remaining cases of homoallelism (3.2\%) were all resolved by Southern blotting; the whole diagnostic process took about 2 weeks.

\section{Distribution of allele size}

We determined the distribution of size of the normal $(\mathrm{CAG})_{n}$ for all individuals $(n=338)$ genotyped (all tests). There were 467 (96.3\%) alleles in class 1 (9-26 CAGs); 18 (3.7\%) in class 2 (27-32 CAGs). The allele with 17 CAGs was by far the most frequent among normal alleles (35.0\%), followed by the 18 -CAGs $(16.5 \%)$ and the 20 CAGs $(9.5 \%)$ alleles.

The distribution of the disease alleles was determined in 191 subjects. For class 3, $n=7$ (3.7\%), range 36-39 CAGs; and for class $4, n=184$ (96.3\%), range 40-94 CAGs. The expanded allele with 42 CAGs was the most common (18.3\%) Figure 1 shows the overall distribution of normal and disease alleles.

\section{Infantile and juvenile cases}

We identified three infantile cases of $\mathrm{HD}$, with $\mathrm{CAG}$ expansions of 67, 90 and 94 units. The affected parent was the father in all cases; all three, with ages at onset of 57 years, presented with Parkinsonism, rigidity, poor school and intellectual performance and dementia (Table 2). One additional case, with a $(\mathrm{CAG})_{66}$, was referred at the age of 26 years and also presented typical symptoms of infantile onset, but no information about age at onset, family history or the affected parent was made available to us.

One juvenile case, with a $(\mathrm{CAG})_{60}$, had maternal transmission. She started typical symptoms, after pregnancy and delivery at the age of 19 years, including a movement disorder, memory loss, muscular weakness and behavioural changes.

Special cases in genetic counselling: 'homozygosity' for the HD mutation, carriers of large normal alleles and 'homoallelism' for a normal gene

None of our patients was a 'full homozygote', that is, carrying two fully expanded alleles; however, we identified two cases, each carrying a fully penetrant (class 4 ) and a reduced penetrance allele (class 3): one patient with 51/39 CAGs, and a presymptomatic subject with 47/36 CAGs (Table 3). The first had onset at 31 years and usual symptoms; HD was present only on his maternal side; he had two children, aged 4 and 6 years, a situation that raised enormous difficulties in genetic counselling. The second was still asymptomatic by age 24 years, had maternal family history only, and no progeny.

In addition, four patients (1.7\%) had both a fully penetrant (class 4) and a large normal allele (class 2). All had a typical clinical presentation and history of HD only on one side of the family. All patients already had some offspring.

We have also identified 13 subjects (3.9\%) having both a class 2 and a class 1 allele; seven (2.1\%) were male subjects.

We detected 20 cases of homoallelism, 5.9\% among all 338 subjects tested; 11 (11.5\%) of all presymptomatic tests, and nine (10.8\%) of the patients excluded for HD; 14 were homoallelic for the most common allele (17 CAGs), four had both alleles with 18 CAGs, one with 19/19 CAGs, and one with a 20/20 CAGs genotype. 


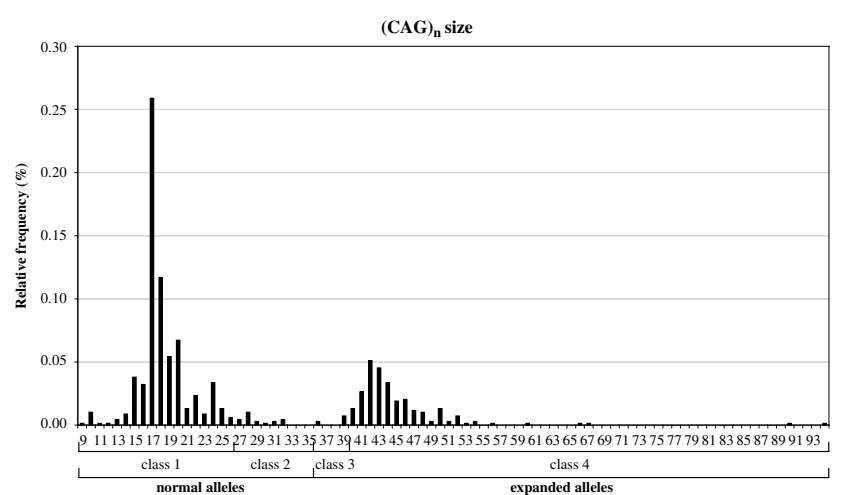

Figure 1 Distribution of the (CAG) $)_{n}$ size in all 676 alleles genotyped: normal (classes 1 and 2 ) and mutated alleles (classes 3 and 4).

\section{Discussion}

Offer of molecular diagnosis for HD, in Portugal, started in 1998 and allowed a more precise knowledge about HD, important namely for the foundation of the Portuguese Association of Huntington Disease, in 2001. It also allowed the comparison of ours with other patient populations and the definition of some difficulties for genetic counselling. Molecular diagnosis of HD was achieved for the first time in $90 \%$ of all the families. The number of patients and families reported reflects under-ascertainment, as this study was not a population-based survey; however, referrals increased steadily over the first 3 years, stabilised in 2001 and suffered a steep decrease during 2002. This indicates that we may be approaching a nearly complete ascertainment of families, and that prevalence of HD in Portugal (10 million) may be between 2 and 5:100000.

\section{Confirmation and exclusion of clinical diagnoses}

Most of the diagnostic referrals were made by neurologists $(90.6 \%)$, a situation similar to that found in the Netherlands $(82.2 \%){ }^{10}$ By contrast, family doctors were predominantly the referring physicians (45.4\%) in British
Columbia, where only $37.5 \%$ of the referrals were made by neurologists. ${ }^{11}$ This can perhaps be explained by the different systems of medical practice in Europe and Canada.

The majority of referrals for confirmation of HD were indeed confirmed. Exclusion of $\mathrm{HD}$ in the remaining patients could be explained by their absent or unknown family history or by atypical symptoms; however, $4.1 \%$ had both a family history and a typical clinical presentation, but a later age at onset. This is higher than previously reported: $2.4 \%{ }^{11,12}$ and $0.8 \% .^{10,13}$ Additional molecular research of these 'HD-like' families is ongoing for known $\left(\mathrm{HDL}^{14}\right.$ and HDL2 ${ }^{15}$ ) and unknown loci.

Among all requests for exclusion, a diagnosis of $\mathrm{HD}$ was made in $16.9 \%$. These had often (but not always) an unusual clinical presentation or absence of family history.

\section{Characterisation of our patient population}

In $5.8 \%$ of the patients with known family history, the closest affected individual was not one of the parents or a sib, but a second or third-degree relative. These cases could either imply nonpenetrance (CAG repeat in the smaller expansion range) or early deaths in their parents, although we cannot exclude some instances of nonpaternity; however, at least $5.3 \%$ had no family history at all-some could also result from 'new' mutations.

This frequency is within the range of values previously reported $(1-8 \%),{ }^{10,11,16}$ and not far from the estimates that indicate a mutation rate of $6-14 \%$ per generation for the HD locus. ${ }^{17}$ 'New' mutations would be explained by further expansion of 'intermediate alleles', usually through the male germ line. ${ }^{18}$ Frequency of large alleles (class 2), among all normal chromosomes in our sample (3.7\%), was considerable (although within ranges previously described, if corrected for the same size intervals. ${ }^{12,19}$ ) This prompted us to undertake a population study of 2000 control alleles, which showed a similar value (unpublished data).

Table 2 Infantile and juvenile cases of HD in Portugal

\begin{tabular}{|c|c|c|c|c|c|c|}
\hline Patient & Sex & $\begin{array}{c}\text { Age at request } \\
\text { (years) }\end{array}$ & CAG repeats & Age at onset (years) & Clinical presentation & Affected parent \\
\hline 1 & $\mathrm{M}$ & 10 & $94 / 17$ & 6 & $\begin{array}{l}\text { Parkinsonism, tremor, } \\
\text { bradykinesia }\end{array}$ & Father \\
\hline 2 & $\mathrm{~F}$ & 12 & $90 / 17$ & 5 & $\begin{array}{l}\text { Rigidity, dementia, poor school } \\
\text { performance, walking almost } \\
\text { impossible }\end{array}$ & Father \\
\hline 3 & $\mathrm{M}$ & 16 & $67 / 17$ & 7 & $\begin{array}{l}\text { Choreic movements, } \\
\text { intellectual capacity decline, } \\
\text { preserved language }\end{array}$ & Father \\
\hline 4 & $\mathrm{M}$ & 26 & $66 / 16$ & Unknown & $\begin{array}{l}\text { Parkinsonism, pyramidal } \\
\text { syndrome, dementia, } \\
\text { ophthalmoparesia }\end{array}$ & $\begin{array}{l}\text { Unknown } \\
\text { family history }\end{array}$ \\
\hline 5 & $\mathrm{~F}$ & 24 & $60 / 19$ & 19 & $\begin{array}{l}\text { Movement impairment, } \\
\text { memory and strength loss, } \\
\text { behavioural changes }\end{array}$ & Mother \\
\hline
\end{tabular}


Table 3 Cases with one expansion and one intermediate, class 2 (cases 1 and 2) or class 3 (cases 3 to 6), allele

\begin{tabular}{|c|c|c|c|c|c|c|c|c|}
\hline Case & Sex & Type of request & $\begin{array}{l}\text { Age at } \\
\text { request } \\
\text { (years) }\end{array}$ & $\begin{array}{l}C A G \\
\text { repeats }\end{array}$ & $\begin{array}{l}\text { Age at on } \\
\text { (years) }\end{array}$ & tClinical presentation & Offspring & $\begin{array}{l}\text { Affected } \\
\text { parent }\end{array}$ \\
\hline 1 & M & Diagnostic & 36 & $51 / 39$ & 31 & $\begin{array}{l}\text { Choreiform movements, } \\
\text { facial tics }\end{array}$ & 2 (4 and 6 years) & Mother \\
\hline 2 & $\mathrm{~F}$ & Presymptomatic & 24 & $47 / 36$ & - & - & 0 & Mother \\
\hline 3 & $M$ & Diagnostic & 41 & $52 / 29$ & 32 & $\begin{array}{l}\text { Choreic movements, tics, } \\
\text { irritability, cognitive } \\
\text { impairment, loss of weight }\end{array}$ & 2 (6 and 7 years) & Father \\
\hline 4 & $\mathrm{~F}$ & Diagnostic & 55 & $42 / 32$ & 50 & $\begin{array}{l}\text { Choreic movements, } \\
\text { hypotonia }\end{array}$ & 2 (28 and 35 years) & Father \\
\hline 5 & $\mathrm{~F}$ & Diagnostic & 33 & $49 / 28$ & 28 & $\begin{array}{l}\text { Choreic movements, } \\
\text { behavioural changes }\end{array}$ & $3(5,16$ and 24 years $)$ & Mother \\
\hline 6 & $\mathrm{~F}$ & Diagnostic & 59 & $43 / 32$ & 51 & Involuntary movements & 2 (26 and 28 years) & Mother \\
\hline
\end{tabular}

Distribution of expanded repeat size was similar to other populations. $^{12}$ Correlation between age at onset and $(\mathrm{CAG})_{n}$ size $\left(r^{2}=0.49\right)$, mean age at onset in HD (43.8 years), and that slightly higher in 'HD-like' patients $(46.2$ years), was also in accordance with previous studies. ${ }^{12,20,21}$

This work illustrates the importance of genotyping patients with no or unknown family history. Molecular testing was also particularly helpful for the diagnosis of later-onset patients ( $\geqslant 60$ years), $13.3 \%$ of all our confirmed patients. This is higher than in reports from Wales $(4.7 \%)^{22}$ and England $\left(3.0 \%>65\right.$ years), ${ }^{23}$ and closer to that in British Columbia (19.6\%). ${ }^{11}$ The high frequency of late-onset cases is important for clinicians, and to identify new families and allow them to be offered presymptomatic testing.

Four infantile cases were found; at least three were paternally transmitted. One juvenile case (onset at age 19 years) was inherited from her mother (Table 2).

\section{Presymptomatic testing}

Our experience showed a sex ratio $(59.4 \%$ of female individuals) in agreement with previous reports. ${ }^{24,25}$ Possible explanations include a greater involvement of women in family and reproductive decisions, and their greater willingness to face difficult decisions and their consequences. This is also consistent with data from testing predispositions to cancer. ${ }^{26}$

As in other reports, ${ }^{25}$ the number of consultands under the age of 20 years (all above 18) was very small. The mean age of those who underwent presymptomatic testing, as well as the frequency of proven carriers, is also in agreement with those found in the UK. ${ }^{25}$ The vast majority had a prior genetic risk of $50 \%$, as previously described. ${ }^{25}$ Whenever a person at $25 \%$ risk requested testing, it has always been possible (except in three cases where the atrisk parent had died) to counsel and test first the parent still at a $50 \%$ risk.

In 12 presymptomatic tests, there was no previous genetic confirmation of HD in a proband: seven belonged to three sibships, where all sibs were sampled at the same time, and at least one was a carrier, thus proving the existence of a CAG expansion in the family; of the remaining five, one had an expansion. The four noncarriers had a family history of HD, but no proband testedthe report issued mentioned, in each case, the possibility of genetic heterogeneity and that a risk could not be completely excluded.

\section{Difficulties in genetic counselling}

In addition, homozygosity for HD (defined in the classical sense of having two mutated alleles), the finding of large normal alleles, and homoallelism (two alleles exactly of the same size) presented difficult issues for genetic counselling.

Two homozygous individuals were identified (Table 3): the first had a typical clinical presentation and age at onset, while the second is still asymptomatic at the age of 24 years: again, this is in agreement with HD being a completely dominant phenotype. ${ }^{27,28}$ Thus, the main question may be if the counsellor should give the consultands their exact genotype (two full mutations, or one fully mutated and one incomplete-penetrance allele), if this has no predictive value for them. In fact, there is an ethical dilemma here: knowledge of the full test result is a right of the consultands and will undoubtedly be important for their decision-making regarding future progeny, if still at a reproductive age; on the other hand, this will imply giving away the genotype on their (adult, minor or yet-to-be born) offspring, which goes against existing guidelines. $^{29}$

Carriers of both a fully penetrant and a large normal allele were not infrequent, and needed a special approach in terms of genetic risks for their progeny. In female subjects (three cases), the risk for their offspring to be affected will still be $50 \%$; but the nonaffected offspring would still be carriers of a large normal allele, which can give rise to a full mutation in their own progeny, if males. In our fourth case, a male subject, the risk for his own offspring was in fact higher than $50 \%$, as the large normal allele may further expand to an incomplete or fullpenetrance allele in that generation. 
Finally, another problem identified was the frequency of normal homoallelism (5.9\%). This implies that further procedures may delay the results in presymptomatic testing and cause major difficulties, particularly for prenatal diagnosis.

\section{Acknowledgements}

We thank all other physicians who referred HD testing to us: MA Ferro, V Passão, P Coutinho, H Santos, J Saraiva, C Costa, JMC Guerra, F Piloto, MHC Fernandes, J Coimbra, J Barros, M Romero, MR Silva, A Palos, AM Fortuna, CP Moura, E Monteiro, MJ Rosas, P Esperança, $L$ Nunes, AC Araújo, JCB Costa, J Proença, J Ferreira, AM Carvalho, B Botelho, M Mota, T Temudo, B Lima, BB Corrêa, D Alves, F Ferreira, J Becho, MM Rosa, C Robalo, G Carneiro, I Mendes, I Morales, MM Costa, TS Silva, TC Aguiar, A Henriques, AM Silva, AP Correia, Â Valença, A Ramos, AA Saraiva, A Leal, A Morganho, B Santiago, B Nunes, C Basilio, C Veira, C Silveira, C Guarda, C Morais, DM Gaspar, D Salgado, E Azevedo, E Parreira, E Calado, FP Silva, F Pita, FR Martins, GG João, H Águas, IMS Matos, I Cinha, I Palma, I Cordeiro, I Santana, J Buisan, J Nunes, J Alcântara, J Guimarães, JP Costa, J Aguiar, JAG Gonçalves, A Tuna, JE Pena, J Figueiredo, JM Castro, L Guerra, M Veloso, MM Dias, M Pinto, MA Santos, ML da Silva, MR Lima, MS Dias, MA Trindade, ML Albuquerque, MTC Pereira, MR Bento, M Marta, M Rodrigues, M Veloso, NMM Canas, P Breia, JMP Monteiro, P Marques, P Tavares, RN Fernandes, RJ Guerra, R Relvas, TM Faria and V Salgado.

We also thank A Luzio, A Ferro, MT Matamá and P Mendonça for their technical support.

\section{References}

1 Martin JB, Gusella JF: Huntington's disease: pathogenesis and management. N Engl J Med 1986; 315: 1267-1276.

2 Harper PS: The epidemiology of Huntington's disease. J Med Genet 1992; 89: 365-372.

3 The Huntington Collaborative Research Group: A novel gene containing a trinucleotide repeat that is expanded and unstable on Huntington's disease chromosomes. Cell 1993; 72: 971-983.

4 The American College of Medical Genetics/American Society of Human Genetics/Huntington Disease Genetic Testing Working Group: Laboratory Guidelines for Huntington Disease Genetic Testing. Am J Hum Genet 1998; 62: 1243-1247.

5 Losekoot M, Bakker B, Laccone F, Stenhouse S, Elles R: A European pilot quality assessment scheme for molecular diagnosis of Huntington's disease. Eur J Hum Genet 1999; 7: 217-222.

6 Hayden MR: Huntington's disease. Berlin, Heidelberg: SpringerVerlag, 1981.

7 Sambrook J, Fritsh EF, Maniatis T: Molecular cloning-a laboratory manual, 2nd edn. Cold Spring Harbor, NY: Cold Spring Harbor Laboratory Press, 1989.

8 Andrew SE, Goldberg YP, Theilmann J, Zeisler J, Hayden MR: A CCG repeat polymorphism adjacent to the CAG repeat in the Huntington disease gene: implications for diagnostic accuracy and predictive testing. Hum Mol Genet 1994; 3: 65-67.

9 Guida M, Fenwick G, Papp AC, Snyder PJ, Sedra M, Prior TW: Southern transfer protocol for confirmation of Huntington's disease. Clin Chem 1996; 42: 1711-1712.
10 Siesling S, Vegter-van de Vlis M, Belfroid RDM, Maat-Kievit JA, Kremer HPH, Roos RAC: Family history and DNA analysis in patients with suspected Huntington's disease. J Neurol, Neurosurg Psychiat 2000; 69: 54-59.

11 Almqvist EW, Elterman DS, MacLeod PM, Hayden MR: High incidence rate and absent family histories in one quarter of patients newly diagnosed with Huntington disease in British Columbia. Clin Genet 2001; 60: 198-205.

12 Kremer B, Goldberg P, Andrew SE et al: A worlwide study of Huntington's disease mutation: the sensitivity and specificity of measuring CAG repeats. N Engl J Med 1994; 330: 1401-1406.

13 Andrew SE, Goldberg YP, Kremer B et al: Huntington disease without CAG expansion: phenocopies or errors in assignments? Am J Hum Genet 1994; 54: 852-863.

14 Moore RC, Xiang F, Monaghan J et al: Huntington disease phenocopy is a familial prion disease. Am J Hum Genet 2001; 69: $1385-1388$.

15 Holmes SE, O'Hearn E, Rosenblatt A et al: A repeat expansion in the gene encoding junctophilin-3 is associated with Huntington disease-like 2. Nat Genet 2001; 29: 377-378.

16 Andrew SE, Goldberg YP, Hayden MR: Rethinking genotype and phenotype correlations in polyglutamine expansion disorders. Hum Mol Genet 1997; 6: 2005-2010.

17 Falush D, Almqvist EW, Brinkmann RR, Iwasa Y, Hayden MR: Measurement of mutational flow implies both a high newmutation rate for Huntington disease and substantial underascertainment of late-onset cases. Am J Hum Genet 2000; 68: $373-385$.

18 Goldberg YP, Kremer B, Andrew SE et al: Molecular analysis of new mutations for Huntington's disease: intermediate alleles and sex of origin effects. Nat Genet 1993; 5: 174-179.

19 Goldberg YP, McMurray CT, Zeisler J et al: Increased instability of intermediate alleles in families with sporadic Huntington disease compared to similar sized intermediate alleles in the general population. Hum Mol Genet 1995; 4: 1911-1918.

20 Snell RG, MacMillan JC, Cheadle JP et al: Relationship between trinucleotide repeat expansion and phenotypic variation in Huntington's disease. Nat Genet 1993; 4: 393-397.

21 Andrew SE, Goldberg YP, Kremer B et al: The relationship between trinucleotide (CAG) repeat length and clinical features of Huntington's disease. Nat Genet 1993; 4: 398-403.

22 James CM, Houlihan GD, Snell RG, Cheadle JP, Harper PS: Lateonset Huntington's disease: a clinical and molecular study. Age Ageing 1994; 23: 445-448.

23 Craufurd D, Dodge A: Mutation size and age at onset in Huntington's disease. J Med Genet 1993; 30: 1008-1011.

24 Simpson SA, Besson J, Alexander D, Allan K, Johnston AW: One hundred requests for presymptomatic testing in Huntington's disease. Clin Genet 1992; 41: 326-330.

25 Harper PS, Lim C, Craufurd D, on behalf of the UK Huntington's Disease Prediction Consortium: Ten years of presymptomatic testing for Huntington's disease: the experience of the UK Huntington's Disease Prediction Consortium. J Med Genet 2000; 37: $567-571$.

26 Evans DGR, Maher ER, Macleod R, Davies DR, Craufurd D: Uptake of genetic testing for cancer predisposition. J Med Genet 1997; 34: $746-748$.

27 Myers RH, Leavitt J, Farrer LA et al: Homozygote for Huntington's disease. Am J Hum Genet 1989; 45: 615-618.

28 Durr A, Hahn-Barma V, Brice A, Pecheux C, Dode C, Feingold J: Homozygosity in Huntington's disease. J Med Genet 1999; 36: 172-173.

29 Working Party of the Clinical Genetics Society: Report on the genetic testing of children. J Med Genet 1994; 31: 785-797. 